\title{
EMPOWERING EMPLOYEES WITH DIGITAL AGILITY: MITIGATION STRATEGIES FOR INFORMATION GLUT
}

\author{
Debra J. Borkovich, Robert Morris University, borkovich@rmu.edu \\ Robert J. Skovira, Robert Morris University, skovira@rmu.edu
}

\begin{abstract}
This study represents a pragmatic approach to understanding the current state of information glut in concert with the mitigating factor of digital agility. A large US global corporation was researched for professional employee and managerial feedback regarding its management of an infinite and unwieldy information glut in the workplace. The findings were analyzed for their respective successful or failed agile technical remedies set-forth by employers to placate the employees and mitigate the consequences of information glut. Although corporate communications publicly portrayed agile technologies and mobile devices as ameliorators to information overload in the professional milieu, interviewees and Informants differed in their interpretations. Results showed that despite the implementation of agile technologies, including mobile tech devices, employees suffered information glut from perceived overload, context collapse, culture shock, and workplace injustices that were exacerbated, not mitigated, by digital agility.
\end{abstract}

Keywords: information glut, digital agility, context collapse, culture shock, information overload

\section{INTRODUCTION}

Everyone knows that successful organizations are agile, most particularly in the Information Age, and perhaps more so now than at any other time. They constantly evolve, change, and transform to meet the needs of their internal and external customers because organizations are human creations. Organizations must adapt to meet social, cultural, and environmental needs to ensure their respective sustainability and viability. When entities refuse to change and evolve, new organizations emerge to replace obsolete ones and Kuhn's (1962) paradigm shift, once again, self-perpetuates. Humans are the instruments of the Information Age and technology (physical, sensory, digital, artificial and virtual) provides the tools. IBM estimates that by 2020, 44 zettabytes of data, the thousand-fold number next up from exabytes, will be generated from all of our computers and mobile tech devices (Hardy, 2016). This paper explores the construct of workplace digital agility, and its power to separate the wheat from the chaff, the meaningful information from the noisy glut.

Digital agility, its historical underpinnings, and its untapped potential to manage information overload has been the topic of subject matter experts for some time. Through the lens of information, communication, social scientists, academics, and management theorists, this paper discusses how agile theories and strategies were applied to one Fortune 500 organizational environment to mitigate potential occurrences of culture shock engendered from the constant glut of information overload. Following the interpretation and analysis of relevant literature, observations and interviews, the authors argue that organizational agility is far from a new concept, but is an underutilized and misunderstood method to ameliorate distinctive and specific occurrences of information deluge and its negative repercussions on the knowledge worker. By soliciting employee perspectives, a professional workplace environment was studied for its digital approaches to the agile management of information glut.

\section{Problem Statement: To be or not to be agile}

Why do some organizations resist change and growth, even to the extent of their technological detriment; and others willingly embrace it? How can the employment of digital agility, often and inexplicably rejected by subject matter experts preferring information silos and echo chambers, be diligently at work in time suspensions of solitude and silence? Why do organizations waste valuable collaborative cooperative brain power consisting of data, information, knowledge and wisdom that could manifest as catalysts toward mutually beneficial innovation, creativity, invention, and passion for the common good? 
We can permit ourselves to be overwhelmed by massive amounts of data and information, or we can choose to be emboldened by its possibilities. Digital Age organizations all experience information overload from time to time, and this phenomenon has already reached critical mass for many.

\section{The Study}

This qualitative approach to inquiry was based upon observations, interviews, and Informant conversations with professional employees of a elephantine Fortune 500 corporation at its Mid-Atlantic US division headquarters. The ethnography was motivated by noted gaps in the literature regarding the application of agile technologies to mitigate or ameliorate information glut in the workplace. The researcher was interested in collecting knowledge-worker feedback to learn how and why their conceptualizations of digital agility helped or hindered employee management of information overload. Results were analyzed and interpreted to refine the findings and develop future recommendations. Not surprisingly, this organization implemented agile remedies with varying degrees of success.

\section{LITERATURE REVIEW}

This section presents a limited historical background and relevant literature precipitating the onset of voluminous information glut in the workplace. The resultant constructs of digital agility, information overload, context collapse, satisficing, bounded rationality, and culture shock are also described as coined and introduced by the theorists.

\section{Historical Perspective}

From the great analog and digital inventions of the Bell Labs scientists, through DARPA's 1969 creation of the internet and Berners-Lee's 1989 development of the World Wide Web, to the current digital gadgets that newly appear on a daily basis rendering yesterday's obsolete, our technologies have accelerated the growth of artificial intelligence far beyond the speed of human comprehension. We want to know, read, view, and learn everything, but alas, the bits and bytes of data fly faster than our human capabilities can assimilate and digest. In a 1939 essay, Bush (1945) prophesized an information retrieval system that would revolutionize our access to unlimited data. Shannon's (1948) brilliant model of communication theory and Weaver's (1949) illuminating semantic approach convinced us that we could share information as long as we knew how to code, send, receive, and decode the message in the same language; and of course, the message had to successfully survive and arrive through the signal disruptions of noise and interference. Shannon solved that problem by conceptualizing digitally transmitted messages, eliminating the common errors of analog messages. Although Shannon was specifically focused on the technological and mathematically quantitative problem of developing a relatively error-free and accurate transmission model, Weaver was particularly interested in conveying meaning and applying semantic understanding to the message with his study of Shannon's correction channel, now commonly referred to as the feedback loop (Gertner, 2012).

Nonaka and Konno (1998) taught us that understanding Zen and finding the "ba" would make communication palatable and comfortable. And Polanyi's (1962) influence led us to the understanding that differences existed between explicit and tacit knowledge and overt and covert meaning, so that we might learn how to read and apply intuitive and sensory signals within our social-cultural environment. Tiwana (2002), Davenport (2003), and Liebowitz (2006) taught us that it was possible to manage knowledge by associating distinctive meanings and a natural progression from data, to information, to knowledge, culminating in the ultimate goal, wisdom.

Debons (2008) extended our human awareness and cognition of events and processes by associating "what, when, where, and who" to the construct of information, and "how and why" to the construct of knowledge in his Augmented Data Information Knowledge (ADIK) System. He metaphorically described his ADIK System as the EATPUTr (event, acquisition, transmission, processing, utilization, and transfer) model. Debons argued that data, information, and knowledge were mere agents to augment human intellect; therefore, "information is [inherently human and] culturally based" (p. 9). He further theorized that the ADIK philosophy embodied a vast interdisciplinary information system, learned as a science, and manifested as a process resulting in meaningful technical, sensory, physical, artificial, tangible, and intangible knowledge products achieved far beyond our sole and very limited human capabilities. 
With all this expert guidance, how could we not manage all this wonderful glut of information? But Simon (1972) pointed out that although all this data, information, and knowledge constantly contributed to our deeper understanding, humans were constrained and confined within our own individually "bounded rationalities" and were only capable of seeking, learning, retaining, remembering, extracting, and applying so much knowledge at any given time. Without overtly realizing it, we were "satisficing" (Simon, 1972), merely applying the portmanteau to our actions by using the best available information, not perfect or all-encompassing, to solve problems and make decisions in our daily lives. "Satisficing" suddenly entered the popular parlance among academics as the moniker associated with a coping mechanism meant to eliminate the excessive information chaos that clouded our judgment.

\section{Digital Agility}

For the purposes of this paper, digital agility refers to the application of technology to assist knowledge-worker professionals and managers in the prosecution of their respective roles and responsibilities. The term "agile" emanates from Larman's (2004) software development process meaning rapid and flexible response to change, maneuverability, and iteration designed to meet the needs of the end-user. When referring to organizational information systems, agility provides the path for constant, flexible, incremental and iterative improvement, including course correction and adaptation. Contemporary businesses espouse shaping strategic agility through digital options (Sambamurthy, Bharadwaj, \& Grover, 2003; Overby, Bharadwaj, \& Sambamurthy, 2006; Doz \& Kosonen, 2010). The US Department of Defense (DoD) espouses that Information Age agility is an imperative to successfully cope with changes in circumstances in a dynamic environment (Alberts, 2011). In concert with $\mathrm{DoD}$, corporations are in agreement that agile technology and organizational management are required to control a dynamically evolving and nimble information system. Digital advantages include competitive prowess and efficiencies of cost, time, and performance. The Digital Age brought with it an illusion of power and control based upon technology, automation, and systems; and the misplaced belief that organizational culture would overcome all these information overload challenges (Atkinson \& Moffitt, 2007).

\section{Information Overload and Culture Shock}

The Digital Age brought us directly to the point of a self-perpetuating information overload that was capable of manifesting itself into a culture shock (Oberg, 1960) of massive proportions. Information overload, a term coined by Gross (1964, p. 856) and popularized by Toffler (1970), refers to the difficulty a person can have understanding an issue, determining options, and making decisions that can be caused by the presence of too much information. Shannon $(1948 ; 1949)$ argued that the most important attribute of a message was the information; and Simon (1972) proffered that "bounded rationality" placed a perimeter of constraints around the maximum amount of information that a human can process at any time.

Psychologists viewed information overload as a bombardment to the senses, a version of sensory overload, causing confusion, distraction, disorientation and lack of responsiveness. Wright (2007, p. 6) argued that "we live in an age of exploding access to information awash in a tsunami of data." Toffler (1970, pp. 350-351) suggested that: "When the individual is plunged into a fast and irregularly changing situation, or a novelty-loaded context ... his predictive accuracy plummets. He can no longer make the reasonably correct assessments on which rational behavior is dependent." Toffler further argued that an individual's exposure to exponential sources of constant information glut engendered overload, long before a person's recognition of the validity of the content or the risk of misinformation.

Postman (1993) provided a vivid description of the anxiety and frustration caused by an over-zealous sensory bombardment of information leading to paralytic culture shock:

Technology increases the available supply of information. As the supply is increased, control mechanisms are needed to cope with new information. When additional control mechanisms are technical, they further increase the supply of information. When the supply of information is no longer controllable, a breakdown in the psychic tranquility and social purpose occurs. Without defenses, people cannot find meaning in their experiences, lose their capacity to remember, and have difficulty imagining reasonable futures. (p. 72) 
To many this information overload phenomenon is exhilarating; to others it is frightening, threatening, even paralytic (Borkovich, 2012). Christensen (2011) argued that disruptive technologies had fluid futures and it was impossible to know when they will erupt into conflict, uncertainty, and risk. For protection, people gravitate to like-minded groups where membership forms cultures and subcultures, and members find solace and security in communities of practice, learned behavior, and shared systems of meaning. Unfortunately, some organizations foster closed cocoon-like societies where terms like change and growth are never uttered; new members are seldom welcomed; and agility is but a dream.

\section{Context Collapse}

Social media giant, Facebook, is facing its own organizational crisis of information overload. Following ten years of exponential growth in its membership (Statista Online, 2016), users are no longer able to routinely support their own personal glut of information from an increasing number of "friends." In 2016, Facebook announced that the construct of context collapse (Wesch, 2008; 2009) was the cause of a decline in people sharing original, personal content, the fuel that powers the money machine at the heart of its social network (Efrati, 2016; Frier, 2016). Context collapse refers to an infinitely possible online audience perpetuated by information overload contrasted to the limited groups a person normally interacts with face-to-face (Vitak, 2012).

Web 2.0 advanced the user community into a virtual reality where ubiquitous internet participation is advocated and welcomed. Information is streaming live at break-neck speed with little regulation or oversight, and a vast opportunity exists to post subjective opinions in lieu of objective information. Postman (1993, p. 70) described "information appear[ing] indiscriminately, directed at no one in particular, in enormous volume and at high speeds, disconnected from theory, meaning, or purpose." A prior study of twenty-two professionally employed adult Facebook users, whom experienced a decade of online participation, were interviewed for their opinions of social media related to information overload, privacy, security, trust, naïveté, and skepticism (Borkovich \& Breese, 2016). Findings evidenced that many users were paralyzed with information glut and the inability to respond meaningfully to a variety of online audiences resulting in context collapse and the abandonment of Facebook.

Successful organizations are also agile, aggressive and volatile, aware of high-energy, fast-paced, rapid-response earners, consumers, and information producers. Many corporations strongly encourage their employees to engage in social media to promote its products and services, recruit employees, advertise its events and contests, and to solicit public good will, ever contributing to the infinite information glut and the potential loss of meaningful context in the workplace. In hindsight, it is apparent that $20^{\text {th }}$ century computing advances all pointed to this inevitable phenomenon of information glut.

\section{METHODOLOGY}

This qualitative study was an interpretative approach to inquiry that focused on adult professional employees of Gotham Inc. whom experienced at least a decade of corporate employment. For the purposes of this study, "Gotham" is a pseudonym employed to shelter the identity of a behemoth US Fortune 500 publicly-traded global business concern. This agile ethnography was accomplished by an embedded researcher with prior knowledge of the organization, and therefore, did not require additional time to learn the inner-workings of the organization. This ninetyday study was operationalized through participant-observation, interviews, and in-depth Informant conversations of a sample size of fifty-six professional and managerial employees $(n=56)$ within a facility population of 282 . The examined artifacts included a variety of laptops, tablets, hot-spots, and mobile tech devices.

This research had a two-fold purpose: 1). How did employees manage perceived information glut in a digitally agile organizational environment? -and-2). How did employees feel about corporate's directive that mandated use of agile technologies and no-cost mobile tech devices would mitigate information glut?

The sample size was purposefully selected by identifying those employees that were salaried professionals and managers, representative of every department in this facility, and whose performance of their respective roles were designated as essential and integral not only to each professional discipline, department, or customer deliverable, but to the success of the overall corporate mission. Table 1 illustrates the overall composition of the study. 


\begin{tabular}{|l|l|}
\hline Table 1. Corporate Composition of the Agile Ethnography \\
\hline Subject & $\begin{array}{l}\text { Gotham Inc. (Subsidiary of a Publicly-traded } \\
\text { Fortune 500 Global U.S. Company) }\end{array}$ \\
\hline Facility & Mid-Atlantic Location \\
\hline Population & 282 Employees (100\%) \\
\hline Sample Size & $\mathrm{n}=56$ Employees (20\% of Population) \\
\hline Informants & 8 \\
\hline Research Period & 90 Calendar Days \\
\hline
\end{tabular}

Ethnographic data were collected via participant-observation, interviews, and confidential Informant conversations. Digital workplace artifacts, such as laptops, tablets, hot-spots, and mobile technology devices, were discussed and examined as eight Informants willingly and eagerly opened up about their systemic use. The interviews were considered semi-structured and the participants were encouraged to share information as their comfort levels allowed. Results were then analyzed and interpreted to further refine the findings and develop future recommendations. Table 2 reflects the sample size demographics.

\begin{tabular}{|l|l|l|l|}
\hline \multicolumn{4}{|c|}{ Table 2. Corporate Composition of the Sample Size } \\
\hline Demographics & Sample Size & $\begin{array}{l}\text { Total } \\
\mathbf{5 6}\end{array}$ & $\begin{array}{l}\text { Percentage } \\
\mathbf{1 0 0} \%\end{array}$ \\
\hline Gender & Male & 36 & $64 \%$ \\
\hline & Female & 20 & $36 \%$ \\
\hline Age & Total & $\mathbf{5 6}$ & $\mathbf{1 0 0 \%}$ \\
\hline & $\geq 36$ Yrs. & 32 & $57 \%$ \\
\hline & $\leq 35$ Yrs. & 24 & $43 \%$ \\
\hline Job Category & Total & $\mathbf{5 6}$ & $\mathbf{1 0 0 \%}$ \\
\hline & Management & 34 & $60 \%$ \\
\hline & Professional & 22 & $40 \%$ \\
\hline Informants & Total & $\mathbf{0 8}$ & $\mathbf{1 0 0 \%}$ \\
\hline & Male & 04 & $50 \%$ \\
\hline & Female & 04 & $50 \%$ \\
\hline
\end{tabular}

Although quantitative survey studies abound for this topic, the research motivation was predicated upon noted gaps in the qualitative literature following the introduction of information overload and technical agility as emerging socialcultural constructs during the latter part of the $20^{\text {th }}$ and early $21^{\text {st }}$ century. This descriptive ethnographic study explored how and why these phenomena occur, contrasted to the quantitative approach of what and how much.

\section{INTERPRETATION}

\section{Preface - Gotham's Evolution}

The question has long been posed: How do long-established traditional companies like one hundred thirty-five yearold Gotham successfully transform from a manufacturing giant to a knowledge-based service information environment? Gotham began this path following the transition from its former domestically jobs-driven CEO, to its new global out-sourcing CEO in 2001. Sixteen years later, the company is still struggling with its shift in strategy and culture from a Six Sigma environment of "energy, energize, edge, and execution" (O'Boyle, 1998), to one of "digital simplification, lean and fast principles, imagination, and agility."

The result was growth and scale with an evolutionary presence around the world. However, although the strategic change to a knowledge-based digital information culture was positive, negative decisions led to the sale of domestic manufacturing plants, massive American jobs loss, and the increase of global employees, products, and services. In the US, employees had to deal with an influx of over-abundant amounts of information from all over the world, different, often incompatible or obsolete ERP systems, contractual language and interpretation barriers, foreign laws, customs, and export/import regulations that were entirely unknown. Fewer US employees processed overwhelming 
amounts of global data with little appreciation, recognition, or a sense of value. If there ever was a time to implement Larman's (2004) agility construct of iterative development, course correction, and flexibility, this was it.

Gotham responded to this new $21^{\text {st }}$ century global context and feedback by making agility and simplification the operating rhythm. Digital solutions in an increasingly inter-connected workplace, advancing and listening to the millennial workforce, and requesting employee engagement and feedback were also imperatives. The new cultural orientation changed from Core Values and Mission Statements to "Gotham Beliefs" to ensure that people changed their frame of thinking to the new way. The "Beliefs" reflected a renewed emphasis on acceleration, agility, lean to go fast, and customer focus. Interestingly, the "Beliefs" were crowd-sourced from the employees representing an agile approach to secure buy-in and capture new internal and external information (Krishnamoorthy, 2015).

\section{DISCUSSION}

\section{Observations and Analyses}

Field notes recorded disintegrating relationships between employees and employers and the increased level of risk that employees were willing to take to perform personal business at work, fostered by a digital knowledge environment that mandated its employees to be "always on." Employees expressed that company-mandated mobile tech devices required multi-tasking, particularly by those employees that followed the company rules to utilize work devices only for work purposes. Some employees recognized and accepted a form of company normative control (Kunda, 2006) and opted to use only personal devices for personal business. Therefore, those rule-bound employees also carried personal smart phones, laptops, tablets, and hot spots for non-work-related purposes requiring a more focused propensity for multi-tasking. Since the rule to use company-provided equipment only for business-related tasks was not enforced, the employees strongly believed that company tacitly encouraged that work equipment also be used for personal business, since this would necessitate that both the equipment and the employee were "always on 24/7/365." For example, during evenings, weekends, holidays, and vacations, if an employee checked the company iPhone for personal emails and texts, he/she would typically check the work email and text accounts, as well. Furthermore, corporate rule enforceability would be difficult because everyone knew that senior management also used work devices during worktime for personal business, too. It was a well-known double standard that no one would be fired for using a company tech device for personal business; however, if the company had another reason to get rid of an employee, the use of company devices and worktime for personal business would be documented in the personnel file as extrinsic evidence representing an additional rationale to fire the employee.

During the interviews, employees were encouraged to extemporaneously offer opinions; however, two identical questions were posed to start the process: "Do the company's mandated technologies and mobile tech devices relieve you of information overload?" - and - "Does all the no-cost tech equipment simplify your workload and increase your agility?" An overwhelming number of replies were a resounding, "No!" Table 3 depicts the participants' demographics followed by a limited selection of summarized comments from the interviews. 


\begin{tabular}{|c|c|c|}
\hline $\begin{array}{c}\text { Adult } \\
\text { Interviewees }\end{array}$ & $\begin{array}{l}\text { Q1: Do Gotham's mandated technologies and mobile tech devices } \\
\text { relieve you of information overload? Why or why not? }\end{array}$ & $\begin{array}{l}\text { Q2: Does the no-cost tech equipment simplify your } \\
\text { workload and increase your agility? Why or why } \\
\text { not? }\end{array}$ \\
\hline \multirow{3}{*}{$\begin{array}{c}\text { Males } \\
(36=64 \%)\end{array}$} & 35 Males Replied "No" to this question. & 35 Males Replied "No" to this question. \\
\hline & $\begin{array}{l}\text { M7 ( } \geq 35 \text { ): "No, tech has not decreased my workload - just the opposite! } \\
\text { The emails, attachments, Jabbers, Colabs, WEBEXes, text messages } \\
\text { never stop and sometimes I just take a walk because I feel bombarded } \\
\text { and can't stop or slow down the communications. The more tech I have, } \\
\text { the more info I receive. I can never catch up and I can't seem to turn the } \\
\text { tech off or myself off! What used to be fun and challenging is not } \\
\text { anymore and keeping up with the deluge of information is impossible!" }\end{array}$ & $\begin{array}{l}\text { M5 ( } \leq 36) \text { : "Does tech make me more agile - NO! I } \\
\text { like spending time with my friends on weekends and } \\
\text { holidays. Now I'm tethered to mobile devices, and } \\
\text { just because Gotham pays full freight, my off-work } \\
\text { time is no longer my free time. My buddies think I'm } \\
\text { crazy to stay at this job and they may be right." }\end{array}$ \\
\hline & \multicolumn{2}{|c|}{$\begin{array}{l}\text { M9 ( } \geq 50) \text { : "I have a security clearance at work and I want to work another } 10 \text { years before I retire. I have to abide by the rules } \\
\text { and I can't take the chance to use company equipment for personal tasks. So I am overloaded with information from multiple } \\
\text { devices. A lot of incoming is complete junk and deleted, but I am tired of trying to keep up with all communication sources and } \\
\text { it is too much information to process. I have serious regrets that I did not accept a Government job with regular hours when I } \\
\text { was younger, but it is too late to change now. I wanted more money so I opted for a corporate job, but look what I gave up - the } \\
\text { chance to have a real personal life. Instead of enjoying my career now, I can't wait for retirement to get some time back." }\end{array}$} \\
\hline \multirow{2}{*}{$\begin{array}{c}\text { Females } \\
(20=36 \%)\end{array}$} & 19 Females Replied "No" to this question. & 19 Females Replied "No" to this question. \\
\hline & $\begin{array}{l}\text { F6 ( } \leq 35) \text { : "Every two years we get new laptops. We also received } \\
\text { iPhones, hotspots, tablets, monitors, docking stations to take home, and } \\
\text { anything else we wanted. We were thrilled and believed all this tech } \\
\text { equipment would eliminate the stress for the work we had to process. } \\
\text { Gotham pays our monthly statements and we don't see them unless we } \\
\text { are queried about a strange-looking line item that has to be explained. } \\
\text { Because Gotham pays for everything and doesn't mind if we work } \\
\text { remotely and use the stuff for personal tasks, I feel responsible to be } \\
\text { available all the time. I don't like this feeling, but that's the way it is." }\end{array}$ & $\begin{array}{l}\text { F3 }(\geq 36) \text { : "I need a work-life balance and I don't } \\
\text { get this at Gotham. My children are in high school } \\
\text { with lots of events and I can't be bothered every } \\
\text { evening with a vibrating phone and beeps for text } \\
\text { messages. No, my life is definitely not simpler, it's } \\
\text { more complicated!" }\end{array}$ \\
\hline $\begin{array}{c}\text { Total }=56 \\
(100 \%)\end{array}$ & \multicolumn{2}{|c|}{$\begin{array}{l}\text { NOTE: One female and one male from the } \leq 35 \text { Age Group expressed that the increased agile technology provided by the } \\
\text { company at no-cost increased productivity and alleviated some information glut because data could be immediately deleted. }\end{array}$} \\
\hline
\end{tabular}

Although every Gotham operating rhythm mandated agility, responsiveness, flexibility and focus, observations and Informant interviews of US employees evidenced a very different scenario. Employee frustration with information glut performed by fewer workers over longer hours resulted in apathy and negativity despite the unlimited no-cost tech resources of mobile devices, laptops, monitors, conference call and telepresence equipment, WEBEX, Internet and social media access, VPN, hot-spots, iPhones, office space and the ability to telecommute via Gotham apps.

Gotham was known to have vast financial, technical, and human resources, with no shortage of cybersecurity, training programs and digital equipment of every ilk. However, this research focused on determining employee feedback to ascertain whether or not these agile corporate strategies were helping or hindering productivity due to an overwhelming influence and constant daily bombardment of disparate information from multiple sources.

Management erroneously expected that assigning multiple mobile digital devices would provide employees the agile process to cope with the frustration and shock of information overload. Despite the abundant digital resources, nocost technical equipment and siloed protected culture, employees were willing to risk loss of income, firing, and public humiliation to salvage perceived lost or cheated personal time taken by the employer due to constant information glut. Figure 1 was developed to depict a user's experiences with information glut and the obstacles and challenges of frustration, context collapse, culture shock, and workplace injustices that were difficult to overcome. 


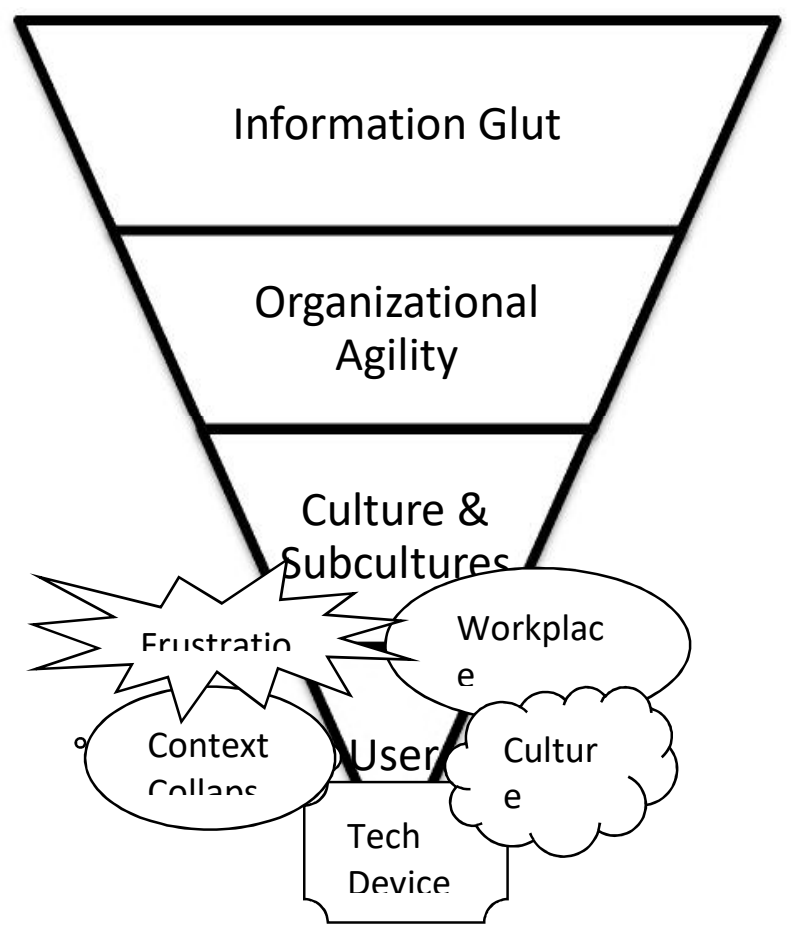

Figure 1. User's Experiences with Info Overload

For comparison, a prior Gotham study (Borkovich, et al., 2016) evidenced similar results of information overload by observing employees at every level spending increasing amounts of non-productive time (personal business) disguised as productive work time. Findings indicated that the culture shock experienced by US employees performing more work with less people over longer hours resulted in the erosion of trust and loyalty, further exacerbated by the employer's mandated requirement to tether its employees to mobile digital technology. Many employees viewed this employer tactic of disregarding earned and accrued leave, weekends and holidays as insensitive and unfair, and critically expressed their opinions of management as "unjust treatment." In this case, employees covertly retaliated against "big brother" by conducting personal business during worktime. Informants reported that personal usage by some disgruntled employees ran as high as $30-50 \%$ of each work day.

Publicly Gotham portrayed agile technology as ameliorators to information overload and a cure-all to frustrated employees. But interviewees differed in their experiences and interpretations. Results showed that professionals and managers alike suffered overwhelming information glut and culture shock that manifested into context collapse and workplace social injustices (Anteby, 2008; Nadisic, 2008) exacerbated, not mitigated or ameliorated, by digital agility and mandated technical equipment. Figure 2, "Organizational Agility Process," was developed to depict the flow of organizational information manifested by agile digital devices resulting in workplace glut, culture shock, context collapse, and social injustices. 


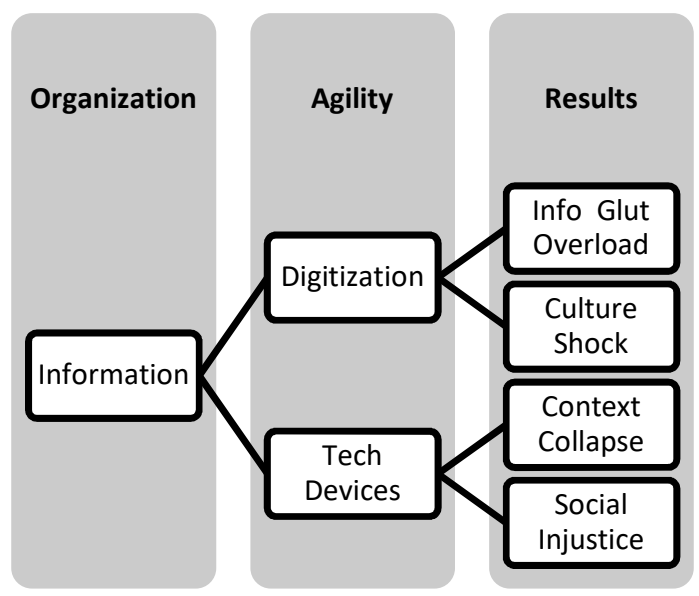

Figure 2. Organizational Agility Process Results

While technology is neutral, people are not (Schmidt \& Cohen, 2013). Connectivity can and will help upend power imbalances, expose corruption and other malevolent forces, and support free-flowing information. However, this study evidenced that the darker side of corporate information overload, such as directed personalization, narrow-casting, siloes, echo chambers and trolling, caused paralytic culture shock resulting in the inability to process work efficiently. Our findings suggested that continued tech agility trends toward conditions that perpetuate being available and "always on $24 / 7 / 365$ " will continually manifest in distrustful employer-employee relationships.

Turkle (2011, p. 295) argued that when we are overwhelmed by an influx of data, "we expect more from technology and less from each other," drawing us to digital solutions that are convenient, responsive, and speedy. Sometimes the only online feedback we hear merely echoes our own preconceived beliefs (Pariser, 2011). Since Gotham's agile edict continues to mandate unlimited tech devices to mitigate or ameliorate information overload, the only way to break this cycle of frustration and covert behavior may be to agree to strike a balance between the perceived benefits of "always on" technology and the comfort and safety of employee personal time when the devices can be "turned off." Through Gotham's lens, can there still be doubt that "information glut" exists in an agile digital workplace?

\section{LIMITATIONS AND FUTURE APPLICATIONS}

This particular study had a number of limitations that the authors wish to address. The research was focused on one large global organization headquartered in the US. A Mid-Atlantic hub facility was observed and the participants were all professional or managerial adults residing exclusively within that location. Future research would benefit from a larger sample size in other US locations, as well as comparisons to smaller businesses and entrepreneurial firms. Additionally, the findings of this exploratory study indicate that future qualitative inquires warrant a larger data pool to generate hard validity and transferability of the results. Other challenges associated with social-cultural studies in a digital knowledge-based workplace environment included obtaining the cooperation, willingness, and honesty of participants to reveal opinions on a sensitive workplace topic; however, large-scale quantitative research project could implement anonymous methods toward a potential generalization of data.

This researcher's interpretations suggested that management is not yet sure how to handle this cultural paradigm shift; therefore, it is further recommended that future studies incorporate systems theory, technical, cultural, and business management research to further address the need to understand and shape the organizational impact, influence of information overload and the perceived usefulness of agility and simplification in a digital environment. Information systems engineering may also realize a structured approach to influence and remedy the intangibles of data glut related to employee behavior, by easing innovation processes, resolving problems rooted in negative behavior or lack of motivation, and ameliorating the frustrations relating to mandated digital equipment and mobile tech devices requiring knowledge-workers to be "always on 24/7/365." 


\section{CONCLUSION}

Our research had a two-fold purpose: 1). How did a corporation's conceptualization of digital agility help or hinder employee management of information glut? - and - 2). Did the no-cost tech equipment simplify or ameliorate the employees' workload and increase agility? Interviews and observations furthered our exploratory research by eliciting even more questions, such as: Why do some organizations resist change and growth, even to the extent of their technological detriment; and others willingly embrace it? How can the employment of digital agility, often and inexplicably rejected by subject matter experts preferring information silos and echo chambers, be diligently at work in time suspensions of solitude and silence? Why do organizations waste valuable collaborative cooperative brain power consisting of data, information, knowledge and wisdom that could manifest as catalysts toward mutually beneficial innovation, creativity, invention, and passion for the common good? We can permit ourselves to be overwhelmed by massive amounts of data and information, or we can choose to be emboldened by its possibilities. Digital Age organizations all experience information overload from time to time, and this phenomenon has already reached critical mass for many.

From this limited study we learned that digital, agile, mobile tech devices, and telecommuting did not help employee management of imformation glut. On a small scale, this study confirmed the theories of several academics, social scientists, and technical experts that information glut exists in the workplace; but agile technologies and mobile tech devices do not always mitigate the challenges presented by the overwhelming and constant overload of information. It was further discovered that other contributing factors, such as increased concern about lack of privacy; loss of security regarding personal information; and distrust of the employer-employee relationship influenced the containment of digital information overload and its relative successful or unsuccessful management. This research discovered that many professional employees experienced context collapse, culture shock, and workplace injustices from the constant bombardment of overwhelming amounts of information arriving at breakneck speed due to various uncontrollable digital collection points. Erroneously identified as the perceived liberators of information glut, successful implementation of technical agility and simplification processes remained challenges for management.

Furthermore, we learned that employees continued to experience difficulty managing information glut within a progressive digitally agile organizational environment. Blurred boundaries existed between professional and personal responsibilities due to the use of agile technologies and company-mandated tech devices complicated by the requirement to be available and "always on 24/7/365." We deduced that many adults are no longer willing to sacrifice their personal health and well-being, time off-the-clock, privacy, trust, reliability, credibility, salary, bonuses, and career potential in exchange for unlimited use of company digital equipment, software, hardware, mobile tech devices, and the privilege of telecommuting. Use of free agile technology is not a fair trade for managing an ever-increasing amount of information glut.

As the lines continue to blur between professional and private lives due to longer hours required to keep up in the digital workplace, other remedies for healthy, happy, and successful employees must be pursued to achieve a worklife balance in addition to agility. At times, when companies fall short in their agile implementation, the failure may not be in those doing their jobs, but the fault of management for not reading the culture correctly and making adjustments. Digital agility, as a lone corporate mantra and remedy, is not the sole panacea to information glut.

\section{REFERENCES}

Alberts, D. S. (2011). The agility advantage: A survival guide for complex enterprises and endeavors. Washington, D.C.: CCRP Publication Series.

Atkinson, S. R., \& Moffat, J. (2007). The agile organization: From information networks to complex effects and agility. Herndon, VA: CCRP Publication Series.

Anteby, M. (2008). Moral gray zones: Side productions, identity, and regulation. Princeton: Princeton Univ. Press.

Borkovich, D. J. (2012). When corporations collide: Information overload. Issues in Information Systems, 13(2), 269-284. 
Borkovich, D., \& Breese, J. (2016). Social media implosion: Context collapse! Issues in Information Systems, 17(4), $167-177$.

Borkovich, D. J., Skovira, R. J., Kohun, F., \& Breese, J. (2016). La perruque in the American digital workplace: Stealing company time. Issues in Information Systems, 17(3), 176-186.

Bush, V. (1945, July). As we may think. Atlantic Monthly, 176(1), 101-108.

Christensen, C. (2011). The innovator's dilemma: The revolutionary book that will change the way you do business ( $4^{\text {th }}$ ed.). New York: HarperCollins Publishers Inc.

Davenport, T. H. (2003). Serenity now! If businesses don't find a way to help the knowledge worker manage information, today's confusion will lead to tomorrow's insanity. CIO, 16(20), 1-2.

Debons, A. (2008). Information Science 101. Lanham, MD: Scarecrow Press.

Doz, Y., \& Kosonen, M. (2010). Embedding strategic agility: A leadership agenda for accelerating business model renewal. Long Range Planning, 43(2-3), 370-382.

Efrati, A. (2016, April 7). Facebook Struggles to Stop Decline in 'Original' Sharing. The Information Online. Retrieved from: https://www.theinformation.com/facebook-struggles-to-stop-decline-in-original-sharing

Frier, S. (2016, April 7). Facebook wants you to post more about yourself. Bloomberg Online. Retrieved from: http://www.bloomberg.com/news/articles/2016-04-07/facebook-said-to-face-decline-in-people-postingpersonal-content

Gertner, J. (2012). The idea factory: Bell Labs and the great age of American innovation. New York: Penguin Press.

Gross, B. M. (1964). The managing of organizations: The administrative struggle. New York: Free Press.

Hardy, Q. (2016, March 14). As a data deluge grow, companies rethink storage. New York Times Online. Retrieved from: http://www.nytimes.com/2016/03/15/technology/as-a-data -deluge-grows-companies-rethinkstorage.html

Krishnamoorthy, R. (2015). GE's culture challenge after Welch and Immelt. Harvard Business Review Online (January 26, 2015). Retrieved from: https://hbr.org/2015/01/ges-culture-challenge-after-welch-and-immelt

Kuhn, T. (1996). The structure of scientific revolutions (3rd ed.). Chicago: The University of Chicago Press. (Original work published 1962)

Kunda, G. (2006). Engineering culture: Control and commitment in a high-tech corporation ( $2^{\text {nd }}$ ed.). Philadelphia: Temple University Press. (Original work published 1992)

Larman, C. (2004). Agile and iterative development. Boston: Addison-Wesley.

Liebowitz, J. (2006). What They Didn't Tell You about Knowledge Management. Lanham, MD: Scarecrow Press.

Nadisic, T. (2008). The Robin Hood effect: Antecedents and consequences of managers using invisible remedies to correct workplace injustice. In Gilliland, S. W., Steiner, D. D., \& Skarlicki, D. P.(Eds.). Justice, morality, and social responsibility of business (pp. 125-153), Charlotte, NC: Information Age Publishing, Inc.

Nonaka, I., \& Konno, N. (1998). The concept of “Ba": Building a foundation for knowledge creation. California Management Review, 40(3), 40-54. 
O’Boyle, T. F. (1998). At any cost: Jack Welch, GE, and the pursuit of profit. New York: Vintage Books.

Oberg, K. (1960). Culture shock: Adjustment to new cultural environments. Practical Anthropology, 7, 177-182.

Overby, E., Bharadwaj, A., \& Sambamurthy, V. (2006). Enterprise agility and enabling role of information technology. European Journal of Information Systems, 15(2), 120-131.

Pariser, E. (2011). The filter bubble: How the new personalized web is changing what we read and how we think. New York: Penguin Books.

Polanyi, M. (1962). Tacit knowing: Its bearing on philosophy problems. Reviews of Modern Physics, 34(4), 601616.

Postman, N. (1993). Technopoly: The surrender of culture to technology. New York: Vintage Books.

Sambamurthy, B., Bharadwaj, A., \& Grover, V. (2003). Shaping agility through digital options: Reconceptualizing the role of information technology in contemporary firms. MIS Quarterly, 27(2), 237-263.

Schmidt, E., \& Cohen, J. (2013). The new digital age: Reshaping the future of people, nations, and businesses. New York: Random House.

Shannon, C. E. (1948). A mathematical theory of communication. The Bell System Technical Journal, 27(July/October), 379-423; 623-656.

Shannon, C., \& Weaver, W. (1949). The mathematical theory of communication. Chicago: Univ. of Illinois Press.

Simon, H. (1972). Theories of bounded rationality. In C. B. McGuire \& R. Radner (Eds.), Decision and Organization (pp. 161-176). Amsterdam: North-Holland Publishing Co.

Statista Online. (2016). Number of monthly active Facebook users worldwide 2016. Statista - The Statistics Portal. Retrieved from: http://www.Statista.com/statistics/264810/number-of-monthly-active-facebookusers/worldwide

Tiwana, A. (2002). The knowledge management toolkit: Orchestrating IT, strategy, and knowledge platforms (2 $2^{\text {nd }}$ ed.). Upper Saddle River, NJ: Prentice Hall.

Toffler, A. (1970). Future shock. New York: Random House.

Turkle, S. (2011). Alone together: Why we expect more from technology and less from each other. New York: Basic Books.

Vitak, J. (2012). The impact of context collapse and privacy on social network site disclosures. J. Broadcast Electronic Media, 56, 451-470.

Wesch, M. (2008, July 31). Context collapse. Digital Ethnography at Kansas State University. Retrieved from: http://mediatedcultures.net/Youtube.context-collapse/

Wesch, M. (2009). YouTube and you: Experiences of self-awareness in the context collapse of the recording webcam. Explorations of Media Ecology, 8(2), 19-34.

Wright, A. (2007). Glut: Mastering information through the ages. Ithaca, NY: Cornell University Press. 